\title{
Facilitating Student Engagement: Teaching with Cases
}

\author{
Fouzia Baki and Aiman Ziout \\ Department of Industrial and Manufacturing Systems Engineering \\ University of Windsor, 401 Sunset Avenue, Windsor, Ontario, Canada N9B 3P4 \\ fouzia1@uwindsor.ca, ziout@uwindsor.ca
}

\begin{abstract}
In this paper, we will show the usefulness of case studies for student engagement. Facilitation of student engagement in a third year engineering course is examined. From experience, we know that content of the course, Industrial Health and Safety, is easy to follow. Finding the right answers to given questions during labs does not require much effort, and consequently, students become disengaged. During winter 2010, we took the challenge of revising the course to encourage students to pursue deep learning during labs by using cases. These cases are based on real situations, gathered by reviewing text books, old project reports, newspapers, etc. We no longer ask students to answer direct questions from materials that have already been presented to them in previous classes. We now give students cases related to the content of that particular lab. We assign two or three students to work together to find answers by reading the given case. The process of case design, the impact observed within a third year engineering course, and lessons that would be valuable to other disciplines will be discussed.
\end{abstract}

\section{Introduction}

The main purpose of Industrial Health and Safety course is to provide industrial engineering students with the knowledge of notable safety considerations related to manufacturing infrastructure, product design and development. Topics are examined include: machine guarding, confined spaces and accident prevention, accident losses, liabilities, and workers' compensation. Today's industrial engineers face a challenge of finding relevant and essential information related to occupational safety and health regulations connected to their works. One of the learning objectives of this course is to familiarize students with current regulations.
This course has three hours of lecture time and also two hours of lab time per week. During the lecture time, instructor combines written materials, films, and other aids to present the teaching and learning materials. During last two years of teaching this course, we identified that it was easy for students to deal with lab assignments because the questions are direct and answers are predictable. As a result, promoting deep learning during labs always had many challenges. In winter, 2010, for the first time, we started to use cases to achieve the learning goal(s) of labs. In this paper, we are going to talk about how these cases were prepared, how the labs were organized, what kind of feedback we received from students, obstacles to implement case based learning, and plan of actions for future. This paper presents an ongoing effort to promote student engagement in Industrial Health and Safety (IH\&S) labs. We are, by no means, in a position to claim absolute effectiveness of case based learning in IH\&S class.

\section{Rationale for Introducing Case Based Learning in IH\&S Labs:}

It is indentified that the fundamental reason for inattentiveness to safety and health (in workplace) is an incomplete understanding of the consequences of neglect [1]. Teaching with cases can serve the purpose of giving lasting impression of the materials taught in IH\&S class because cases provoke discussion, highlight issues and stimulate awareness of problems [2]. Case studies facilitate critical thinking by requiring students to identify principles and theories present in actual situations, thereby building analytical skills [2, 3]. Instructors and graduate assistant also benefit by rethinking their approach to teaching (when they use cases as teaching and learning tools) [4]. For example, using case studies could serve to renew instructors' and graduate assistants' interest in 
course material, as a result, will create a higher level of enthusiasm that hopefully will come across to the students. Thus, both students and instructors can benefit from implementation of case based approach in IH\&S labs.

\section{Preparation of Cases}

Cases are occasions for teaching [2]. Before preparing the labs, we made sure that the outcome(s) of a particular lab was clearly identified. We looked for a case that could provide occasions to identify and analyze

- hazardous situations that led to an accident,

- ways to prevent these types of accidents by implementing techniques and principles learnt in the class,

- laws and regulations that were violated,

- the ethical responsibility of all stakeholders involved

We thoroughly examined texts, internet resources, published government reports, newspaper articles, and also projects reports that collected from students of the same course during last two years. Selection of cases will need to meet the learning outcomes of the lab. This might involve changing or rearranging course outcomes to give students incremental learning opportunities. We wrote the cases to make sure that it was well written and carefully edited. The possibility of using video materials to enhance students' connection to the real world workplaces related to that case was also examined.

\section{How Labs Were Organized}

The IH\&S class at the University of Windsor mostly has third year industrial engineering students. Sometimes we have one or two fourth year Human Kinetics students in the class. It is a small class. The average number of students in this class is around 25. During the lab, students were separated in small groups. All groups worked on the same case during a particular lab. But, the questions that to be answered by each group were different. First, we gave students time to read the case individually. Later they were allowed to discuss the case and the questions they needed to answer in the group. One of the group members was responsible to write down the answers. Answers should be written clearly, which was collected at the end of the lab for marking. Students were encouraged to ask questions for clarification to the facilitator of the labs (most of the time the graduate assistant is the facilitator). Students were allowed to read texts, class notes and search internet to clarify their findings. Students needed to finish their group work in a certain period of time. After group work was complete, the facilitator started asking questions related to the case to all groups. During the question and answer period, students were allowed to debate about their personal opinion. It helped students to see points beyond the written answers. A portion of lab marks were allocated to students' participation in discussion.

\section{Feedback from Students}

We did not have chance to gather written feedback from students yet. We ask students to give their feedback verbally after each lab. A small portion of discussion time was allocated for this purpose. Students' feedbacks are unofficially documented in point form on the board. The common feedback was that students found case based learning forced them to think about the topics in depth. Students also informed us that discussion part of the lab helped them to ethical dimension of the topic. Students appreciated our initiatives. Their overall performance gradually improved throughout the semester.

\section{Difficulties in Implementing Case- based Learning in IH\&S Labs}

Each week, we used many hours to find new cases. This process was not only inefficient in terms of workload of instructor and graduate assistant, but also it did not promote incremental learning. Cases were gathered as we progress through the class. So, it was very difficult to organize cases in a format that could have promoted incremental learning. Sometimes, we found that difficulty levels of cases and questions were not consistent.

\section{Future Plan}

We have big plan for teaching Industrial Health and Safety course in winter 2011. We plan to design and develop reusable worksheets containing cases, questionnaires, databases and problems for Industrial Health and Safety (IH\&S) labs. The design and development of 
worksheets will give equal emphasis to knowledge discovery and experiential learning. The process of case design, the impact observed within a third year engineering course, and lessons that would serve as a model to promote the learning-centred culture/practice for other courses in engineering and other discipline.

The steps we are planning to take before teaching next winter's IH\&S class are as follows:

During summer, 2010, we will collect information from published literature regarding creating effective cases. We will visit University of Western Ontario Business School, where case development process is already well established and regularly preached and practiced. We also are thinking about bringing in Don Woods or other expert in Problem Based Learning (PBL) to our campus with the help of Centre for Teaching and Learning (CTL) at the University of Windsor. We will apply for the permission from ethics committee to use students' written inputs in designing lab materials. We will also continue attending workshops and seminars that would help us understanding how to implement experiential learning techniques in IH\&S labs.

(ii) At the beginning of fall 2010, questionnaires will be given to the students who took IH\&S course during winter 2010 to find out what aspects of labs using cases did and did not work for them. They will also be encouraged to give suggestions for improvements. Students' feedback will be analyzed and evaluated. Students Evaluation of Teaching (SET) score of the instructor from winter 2010 will also be evaluated to find additional information about the course.

(iii) The next step will begin around October, 2010. This process will include development of cases from texts, internet, published government reports, newspaper articles, and past project reports submitted by students in this course.
Selection of cases will need to meet the outcomes of each lab. This might involve changing or rearranging course outcomes to give students incremental learning opportunities. These cases have to be well written and carefully edited by experienced people. The possibility of making and using video materials to enhance students' connection to the real world workplaces will be examined.

(iv) In December 2010, course website will be set up for winter, 2011 class. In winter, 2011, developed cases will be given to students during labs. Students' learning experience will be carefully documented. It will be done by performing formal surveys in labs. We will also observe and compare students' performance of semester of winter, 2010 and of winter, 2011.

(v) Written report will be developed with the experience of this process at the end of winter 2011 or beginning of summer, 2011.

\section{References}

[1] W.H. Stewart, D. E. Ledgerwood, and R.C. May, Educating business schools about safety \& health Is no accident, Journal of Business Ethics, Vol. 15, No. 8, Aug., 1996, pp. 919-926.

[2] R.A. Carson and R. Higgs, Case method, Journal of Medical Ethics, Vol. 12, No. 1, pp. 36-39, Mar., 1986.

[3] L. Wolfer and T. E. Baker, Teaching organized crime patterns: An active learning approach, Journal of Criminal Justice Education, Vol. 11, No. 1, 2000, pp. 79-96.

[4] J.C. Kunselman and K. A. Johnson, Using the case method to facilitate learning, College Teaching, Vol. 52, No. 3, pp. 87-92, Summer, 2004. 